\title{
The Risk of Herpes Zoster in Patients with Non-small Cell Lung Cancer according to Chemotherapy Regimens: Tyrosine Kinase Inhibitors versus Cytotoxic Chemotherapy
}

\author{
Ji Young Choi, MD ${ }^{1}$ \\ Miso Kim, MD2 \\ Bhumsuk Keam, MD, PhD² \\ Tae Min Kim, MD, PhD2 \\ Dong-Wan Kim, MD, PhD² \\ Dae Seog Heo, MD, PhD² \\ Seong Jin Jo, MD, PhD ${ }^{1,3}$
}

Departments of ${ }^{1}$ Dermatology and ${ }^{2}$ Internal Medicine, Seoul National University Hospital, Seoul, ${ }^{3}$ Center for Skin Cancer and Adverse Skin Reaction to Chemotherapeutics, Seoul National University Cancer Hospital, Seoul, Korea
Correspondence: Seong Jin Jo, MD, PhD Department of Dermatology, Seoul National University Hospital and Center for Skin Cancer and Adverse Skin Reaction to Chemotherapeutics, Seoul National University Cancer Hospital, 101 Daehak-ro, Jongno-gu, Seoul 03080, Korea

Tel: 82-2-2072-4916

Fax: 82-2-742-7344

E-mail: sj.jo@snu.ac.kr

Received October 16, 2017

Accepted April 2, 2018

Published Online April 5, 2018

\begin{abstract}
Purpose
Despite the successful use of tyrosine kinase inhibitors (TKIs) in cancer patients, their effect on herpes zoster development has not been studied. The aim of this study was to evaluate and compare the effects of epidermal growth factor receptor (EGFR) TKI and cytotoxic chemotherapy on the risk of herpes zoster development in non-small cell lung cancer (NSCLC) patients.
\end{abstract}

\section{Materials and Methods}

We conducted a medical review of all eligible NSCLC patients in Seoul National University hospital between 2002 and 2015. We classified patients based on whether they previously underwent EGFR TKI therapy into either the TKI group or the cytotoxic group. We compared the incidence rates of herpes zoster during TKI therapy and cytotoxic chemotherapy. Additionally, the longitudinal risk of herpes zoster from TKls was analyzed using the incidence rate ratio (IRR) of the TKI group to the cytotoxic group and the log-rank test of the KaplanMeier method.

\section{Results}

Of the 2,981 NSCLC patients, 54 patients (1.54\%) developed herpes zoster. In the TKI group (2,002 patients), the IRR of herpes zoster during TKI therapy compared to that during cytotoxic chemotherapy was 1.05 (95\% confidence interval [Cl], 0.53 to 2.09). The IRR of the TKI group compared to the cytotoxic group was 1.33 (95\% Cl, 0.64 to 2.76). The KaplanMeier cumulative risk of both groups was not significantly different.

\section{Conclusion}

Our results show that the incidence rate of herpes zoster in the TKI group was not statistically different from the incidence in the cytotoxic group during and after chemotherapy in NSCLC patients.

\section{Introduction}

Herpes zoster, which manifests as a painful vesicular rash, is caused by the reactivation of the varicella-zoster virus (VZV) that lies dormant within dorsal root ganglia cells. Despite the common self-limiting clinical course of VZV, it often persists and causes chronic complications such as postherpetic neuralgia, cranial nerve palsy, polyneuritis, and

\author{
Key words \\ Herpes zoster, Epidermal growth factor receptor, \\ Cytotoxic chemotherapy, Non-small-cell lung carcinoma, \\ Gefitinib, Erlotinib
}


the general population [6,7].

In cancer patients, cytotoxic chemotherapy agents have been used as one of the major treatment modalities. However, as cytotoxic chemotherapy agents target rapidly proliferating cells, these agents inevitably affect epithelial cells, immune-related cells, and hematopoietic cells, which leads to the development of cutaneous, infectious, and hematologic adverse effects. To minimize these adverse effects and to overcome the lack of specificity against cancer cells, molecular targeted chemotherapy has been developed. It targets specific genes or oncoproteins found in cancer cells and works by interfering with specific molecules required for tumor development and growth $[8,9]$. Owing to its specificity towards cancer cells, molecular targeted chemotherapy has been reported to be more tolerable and less toxic to immune and hematologic cells than cytotoxic chemotherapy agents. Consequently, it can be assumed that the risk of herpes zoster is lower in patients receiving molecular targeted chemotherapy than in patients receiving conventional cytotoxic chemotherapy.

Gefitinib and erlotinib, which are small molecule tyrosine kinase inhibitors (TKIs) that target the tyrosine kinase domain of the epidermal growth factor receptor (EGFR), have been successfully introduced and have become standard treatment for EGFR mutant non-small cell lung cancer (NSCLC) [10]. Patients receiving gefitinib and erlotinib do not typically show myelosuppression, neuropathy, alopecia, or severe nausea, which are common side effects of traditional cytotoxic agents. Instead, the major toxicities of gefitinib and erlotinib are dermatologic problems including papulopustular eruption, xerosis, and paronychia [11,12].

However, the effect of EGFR TKIs on herpes zoster has not been studied. Despite the expectation that EGFR TKIs would be less toxic to immune-related cells, there have been a few cases of viral infection or viral reactivation upon EGFR TKI use. Wnorowski et al. [11] described a patient who developed a severe skin eruption followed by herpes zoster superinfection upon erlotinib use, and Bui and Wong-Sefidan [13] reported hepatitis $B$ virus reactivation after erlotinib withdrawal. However, there also have been various studies showing that EGFR TKIs have anti-viral effects against human papillomavirus (HPV), hepatitis $\mathrm{C}$ virus (HCV), and poxvirus [14-18].

In this study, we aimed to investigate the effect of EGFR TKIs, compared to cytotoxic chemotherapy, on the risk of developing herpes zoster in patients with lung cancer. NSCLC patients, whose standard treatments include both conventional cytotoxic chemotherapy and EGFR TKIs, are considered an appropriate population for our study.

We performed the study in two parts: first, we investigated the incidence rates of herpes zoster during TKI regimens and cytotoxic regimens in patients who have received both TKI and cytotoxic chemotherapy. Second, we examined the effect of TKI regimens on the longitudinal risk of herpes zoster by comparing the incidence in patients who had received TKIcontaining regimens with the incidence in patients who had received cytotoxic chemotherapy regimens only.

\section{Materials and Methods}

\section{Study population and data collection}

Subjects were selected from a consecutively collected cancer patient registry that included NSCLC patients. Among the registered NSCLC patients, patients who were at initial stage IIIB/IV or recurred after operation and consequently had received chemotherapy in the Seoul National University Hospital from 2002 to 2015 were selected [19,20]. We collected data on patient characteristics and clinical features, including demographic information (age and sex), smoking history, Eastern Cooperative Oncology Group (ECOG) performance status, clinical presentation of NSCLC at the beginning of chemotherapy, history of radiotherapy, and history of chemotherapy from patient medical records. The number of chemotherapy regimens, types of each regimen, and duration of chemotherapy for each patient were examined in detail. Chemotherapy regimens were classified into two categories: (1) EGFR TKI regimens, which includes gefitinib and erlotinib; and (2) cytotoxic regimens, which includes gemcitabine, carboplatin, cisplatin, docetaxel, paclitaxel, vinorelbine, and etoposide. The patients who had received EGFR TKI regimens were classified as the TKI group, and those who had never received an EGFR TKI regimen and received the cytotoxic regimen only were classified as the cytotoxic group. In the present study, we did not consider the status of EGFR mutation into the classification because EGFR TKIs are commonly incorporated as second- or thirdline chemotherapy in patients with no EGFR mutation and unknown EGFR mutation status.

\section{Risk of herpes zoster during and after administration of the EGFR TKI regimen}

First, the frequency of herpes zoster was compared between the EGFR TKI and cytotoxic groups and further analyzed according to the clinical variables.

In order to compare the risks of the TKI regimen-related herpes zoster and cytotoxic regimen-related herpes zoster, the incidence rate of herpes zoster during the periods of TKI (TKI regimen period) and cytotoxic regimens (cytotoxic regimen period) was compared in the TKI group. The TKI regi- 


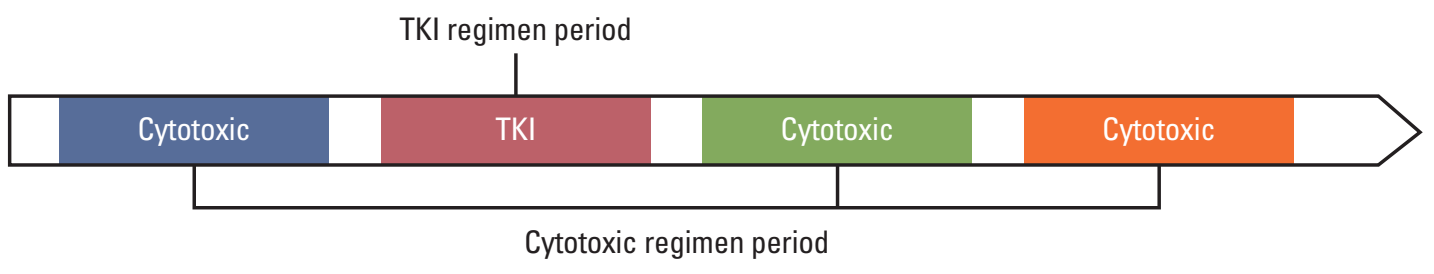

B
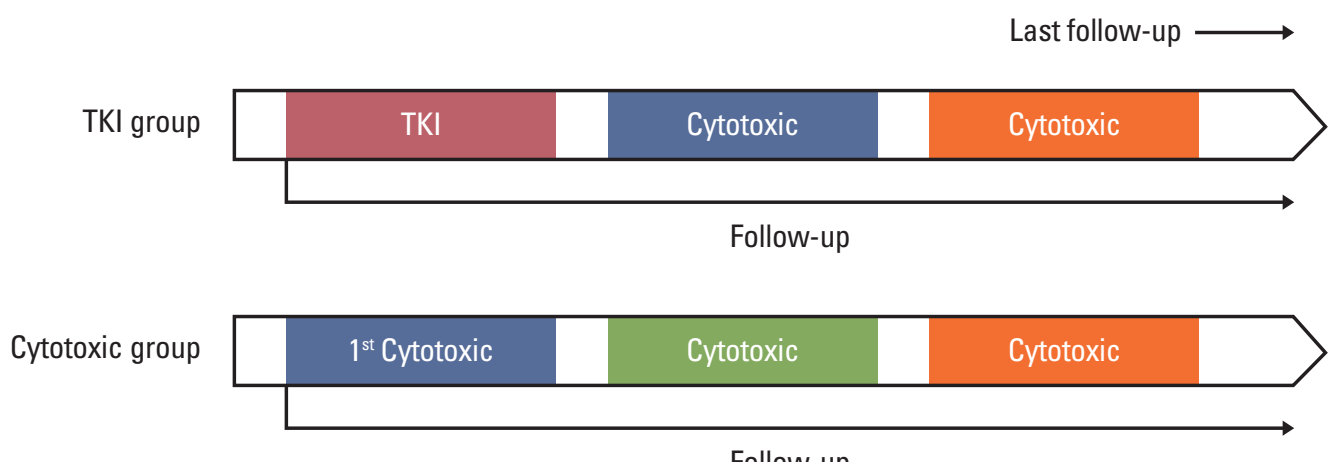

Follow-up

Fig. 1. Definition of the tyrosine kinase inhibitor (TKI)/cytotoxic regimen period and the TKI/cytotoxic groups. (A) The TKI regimen period was defined as the total treatment period treated with epidermal growth factor receptor (EGFR) TKI and the cytotoxic regimen period was defined as the total period treated with cytotoxic chemotherapy. (B) The TKI group was defined as the patients who had received at least one course of EGFR TKI and the cytotoxic group was defined as the patients who had received the cytotoxic-regimen only. The incidence of herpes zoster that occurred after the initiation of the first chemotherapy was included in the study.

men period was defined as the total treatment period a patient was treated with TKIs, and the cytotoxic regimen period was defined as the total period a patient was treated with cytotoxic chemotherapy (Fig. 1A). The development of herpes zoster during the TKI regimen period was considered TKI regimen-related herpes zoster, while the development during the cytotoxic regimen period was cytotoxic regimenrelated herpes zoster.

To determine if the TKI regimen has any effects on the longitudinal risk of herpes zoster, we compared the cumulative incidence rate of herpes zoster between the TKI and cytotoxic groups. In the TKI group, the event of herpes zoster development after the initiation of the TKI regimen was counted; in the cytotoxic group, the event of herpes zoster development after the first chemotherapy regimen was counted (Fig. 1B).

\section{Statistical analysis}

The frequency of herpes zoster depending on patient characteristics and clinical features were compared using chisquare tests. To compare the incidence rate of herpes zoster during the TKI and cytotoxic regimen periods, the incidence rate was analyzed in the unit of occurrence per 100 personyears (PY) and the incidence rate ratio (IRR) of the TKI regimen period to the cytotoxic regimen period and its $95 \%$ confidence interval (CI) were analyzed by Poisson regression.

In our analysis of the longitudinal risk of herpes zoster, we followed each individual up to the last visit to our institution until October 2015. The starting points were defined as the use of first TKIs in the TKI group and as the use of first cytotoxic agents in the cytotoxic group. Before the analysis, propensity score matching was performed to reduce selection bias between the TKI and cytotoxic groups. The longitudinal risk of herpes zoster according to chemotherapy 
Table 1. Patient characteristics and frequency of herpes zoster development in the TKI and cytotoxic groups

\begin{tabular}{|c|c|c|c|c|c|c|c|}
\hline & \multirow{2}{*}{ Total } & \multicolumn{2}{|c|}{ Cytotoxic group } & \multirow{2}{*}{ p-value } & \multicolumn{2}{|c|}{ TKI group } & \multirow{2}{*}{ p-value } \\
\hline & & $\mathbf{H Z ( - )}$ & $\mathrm{HZ}(+)$ & & $\mathrm{HZ}(-)$ & $\mathbf{H Z}(+)$ & \\
\hline No. of patients & 2,981 & 966 & 13 & & 1,969 & 33 & \\
\hline \multicolumn{8}{|l|}{ Sex } \\
\hline Male & $1,790(60.1)$ & $762(78.9)$ & $9(69.2)$ & $0.491^{\text {a) }}$ & $1,002(50.9)$ & $17(51.5)$ & $>0.999^{\mathrm{a})}$ \\
\hline Female & $1,191(40.0)$ & $204(21.1)$ & $4(30.8)$ & & $967(49.1)$ & $16(48.5)$ & \\
\hline \multicolumn{8}{|l|}{ Age (yr) } \\
\hline$<60$ & $1,101(36.9)$ & $282(29.2)$ & $4(30.8)$ & $>0.999^{\mathrm{a})}$ & $800(40.6)$ & $15(45.5)$ & $0.595^{\mathrm{a})}$ \\
\hline$\geq 60$ & $1,880(63.1)$ & $684(70.8)$ & $9(69.2)$ & & $1,169(59.4)$ & $18(54.6)$ & \\
\hline \multicolumn{8}{|l|}{ Smoking status } \\
\hline Never smoker & $1,292(47.0)$ & $209(24.2)$ & $5(41.7)$ & $0.179^{a)}$ & $1,061(57.5)$ & $17(54.8)$ & $0.855^{\mathrm{a})}$ \\
\hline Current or ex-smoker & $1,458(53.0)$ & $654(75.8)$ & $7(58.3)$ & & $783(42.5)$ & $14(45.2)$ & \\
\hline \multicolumn{8}{|l|}{ ECOG performance status } \\
\hline 0 & $146(4.9)$ & $63(6.5)$ & $1(7.7)$ & $0.301^{\mathrm{b})}$ & $81(4.1)$ & $1(3.0)$ & $0.618^{\mathrm{b})}$ \\
\hline 1 & $1,336(44.8)$ & $360(37.3)$ & $4(30.8)$ & & $954(48.5)$ & $18(54.6)$ & \\
\hline$\geq 2$ & $410(13.8)$ & $88(9.1)$ & 0 & & $317(16.1)$ & $5(15.2)$ & \\
\hline Missing & $1,089(36.5)$ & $455(47.1)$ & $8(61.5)$ & & $617(31.3)$ & $9(27.3)$ & \\
\hline \multicolumn{8}{|l|}{ Stage } \\
\hline Initial stage IIIB or IV & $2,491(83.6)$ & $809(83.8)$ & $12(92.3)$ & $0.705^{\mathrm{a})}$ & $1,645(83.5)$ & $25(75.8)$ & $0.237^{\mathrm{a})}$ \\
\hline Recurrence after operation & $490(16.4)$ & $157(16.3)$ & $1(7.70)$ & & $324(16.5)$ & $8(24.2)$ & \\
\hline \multicolumn{8}{|l|}{ Radiation therapy } \\
\hline No & $2,520(84.5)$ & $868(89.9)$ & $11(84.6)$ & $0.634^{\mathrm{a})}$ & $1,615(82.0)$ & $26(78.8)$ & $0.647^{\mathrm{a})}$ \\
\hline Yes & $461(15.5)$ & $98(10.1)$ & $2(15.4)$ & & $354(18.0)$ & $7(21.2)$ & \\
\hline \multicolumn{8}{|l|}{ No. of lines of chemotherapy } \\
\hline$\leq 2$ & $1,507(50.6)$ & $757(78.4)$ & $4(30.8)$ & $<0.001^{\mathrm{a})}$ & $736(37.4)$ & $10(30.3)$ & $0.471^{\text {a) }}$ \\
\hline$\geq 3$ & $1,474(49.5)$ & $209(21.6)$ & $9(69.2)$ & & $1,233(62.6)$ & $23(69.7)$ & \\
\hline \multicolumn{8}{|l|}{ Duration of chemotherapy } \\
\hline$<1 \mathrm{yr}$ & $1,783(59.8)$ & $828(86.1)$ & $5(38.5)$ & $<0.001^{\text {a) }}$ & $941(53.0)$ & $9(28.1)$ & $0.007^{\mathrm{a})}$ \\
\hline$\geq 1 \mathrm{yr}$ & $998(33.5)$ & $134(13.9)$ & $8(61.5)$ & & $833(47.0)$ & $23(71.9)$ & \\
\hline
\end{tabular}

Values are presented as number (\%). TKI, tyrosine kinase inhibitor; HZ, herpes zoster; ECOG, Eastern Cooperative Oncology

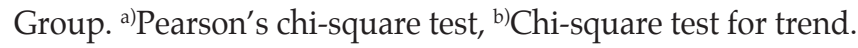

regimens was analyzed by calculating the IRR of the TKI group to the cytotoxic group with the log-rank test in the Kaplan-Meier method.

The analyses were performed using SPSS ver. 17.0 (SPSS Inc., Chicago, IL) and R software (ver. 3.2.2; Institute for Statistics and Mathematics, Vienna University of Economics and Business, Vienna, Austria; available at http://www.r-project.org/index.html). Two-sided p-values of less than 0.05 were statistically significant.

\section{Ethical statement}

The information on the occurrence of herpes zoster was obtained by the review of medical records. This study was approved by the institutional review board of Seoul National University Hospital with a waiver of informed consent (IRB
No. H-1701-043-822) and performed in accordance with the principles of the Declaration of Helenski.

\section{Results}

\section{Study population}

From 2002 to 2015, a total of 2,981 NSCLC patients, including 1,790 men $(60.0 \%)$ and 1,191 women $(40.0 \%)$, were enrolled in the study. The mean age of the study population was $62.37 \pm 11.07$ years. As presented in Table 1, 83.6\% and $16.4 \%$ of the patients received chemotherapy due to stage IIIB/IV status at diagnosis and recurrence after surgery, 
Table 2. Incidence rates of herpes zoster during the periods of TKI regimen and cytotoxic regimen

\begin{tabular}{|c|c|c|c|c|c|c|c|c|}
\hline & \multicolumn{3}{|c|}{ TKI regimen period } & \multicolumn{3}{|c|}{ Cytotoxic regimen period } & \multicolumn{2}{|c|}{ IRR } \\
\hline & $\begin{array}{l}\text { No. of } \\
\text { events }\end{array}$ & PY & $\begin{array}{c}\text { Incidence rate } \\
\text { (per } 100 \text { PYs) }\end{array}$ & $\begin{array}{l}\text { No. of } \\
\text { events }\end{array}$ & PY & $\begin{array}{c}\text { Incidence rate } \\
\text { (per } 100 \text { PYs) }\end{array}$ & Mean & $95 \% \mathrm{CI}$ \\
\hline Total TKI group $(n=2,002)$ & 16 & 1,189 & 1.35 & 17 & 1,332 & 1.28 & 1.05 & $0.53-2.09$ \\
\hline Gefitinib group $(n=1,635)$ & 12 & 1,062 & 1.13 & 11 & 1,042 & 1.06 & 1.07 & $0.47-2.43$ \\
\hline Erlotinib group $(n=488)$ & 4 & 197 & 2.03 & 6 & 380 & 1.58 & 1.28 & $0.36-4.55$ \\
\hline
\end{tabular}

TKI, tyrosine kinase inhibitor; IRR, incidence rate ratio; PY, person-years; CI, confidence interval.

Table 3. Patient characteristics of the TKI and cytotoxic groups before and after propensity score matching

\begin{tabular}{|c|c|c|c|c|c|c|}
\hline & \multicolumn{2}{|c|}{ Before matching } & \multirow[b]{2}{*}{ p-value } & \multicolumn{2}{|c|}{ After matching } & \multirow[b]{2}{*}{ p-value } \\
\hline & $\begin{array}{c}\text { Cytotoxic } \\
\text { group }(n=979)\end{array}$ & $\begin{array}{l}\text { TKI group } \\
(n=2,002)\end{array}$ & & $\begin{array}{c}\text { Cytotoxic } \\
\text { group }(n=979)\end{array}$ & $\begin{array}{c}\text { TKI group } \\
(n=979)\end{array}$ & \\
\hline \multicolumn{7}{|l|}{ Sex } \\
\hline Male & $771(78.8)$ & $1,019(50.9)$ & $<0.001^{\mathrm{a})}$ & $771(78.8)$ & $756(77.2)$ & $0.445^{\mathrm{a})}$ \\
\hline Female & $208(21.2)$ & $983(49.1)$ & & $208(21.2)$ & $223(22.8)$ & \\
\hline \multicolumn{7}{|l|}{ Age (yr) } \\
\hline Mean \pm SD & $64.31 \pm 10.11$ & $61.42 \pm 11.41$ & $<0.001^{\mathrm{b})}$ & $64.31 \pm 10.11$ & $64.17 \pm 10.39$ & $0.767^{\mathrm{b})}$ \\
\hline \multicolumn{7}{|l|}{ Operation } \\
\hline Yes & $158(16.1)$ & $332(16.6)$ & $0.793^{\mathrm{a})}$ & $158(16.1)$ & $150(15.3)$ & $0.664^{\text {a) }}$ \\
\hline No & $821(83.9)$ & $1,670(83.4)$ & & $821(83.9)$ & $829(84.7)$ & \\
\hline \multicolumn{7}{|l|}{ Radiotherapy } \\
\hline Yes & $100(10.2)$ & $361(18.0)$ & $<0.001^{\mathrm{a})}$ & $100(10.2)$ & $80(8.2)$ & $0.137^{\mathrm{a})}$ \\
\hline No & $879(89.8)$ & $1,641(82.0)$ & & $879(89.8)$ & $899(91.8)$ & \\
\hline \multicolumn{7}{|l|}{ ECOG performance status } \\
\hline 0 & $64(12.4)$ & $82(6.0)$ & $<0.001^{\mathrm{c})}$ & $64(12.4)$ & $39(6.9)$ & $0.002^{c)}$ \\
\hline 1 & $364(70.5)$ & $972(70.6)$ & & $364(70.5)$ & $407(71.8)$ & \\
\hline$>2$ & $88(17.1)$ & $322(23.4)$ & & $88(17.1)$ & $121(21.3)$ & \\
\hline \multicolumn{7}{|l|}{ Smoking status } \\
\hline Never smoker & $214(24.5)$ & $1,078(57.5)$ & $<0.001^{\mathrm{a})}$ & $214(24.5)$ & $335(37.9)$ & $<0.001^{\text {a) }}$ \\
\hline Current or ex-smoker & $661(75.5)$ & $797(42.5)$ & & $661(75.5)$ & $549(62.1)$ & \\
\hline
\end{tabular}

Values are presented as number (\%) unless otherwise indicated. TKI, tyrosine kinase inhibitor; SD, standard deviation;

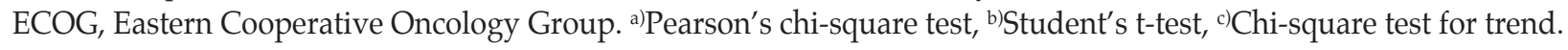

respectively. Of the patients, $84.5 \%$ received radiation therapy, $49.5 \%$ received more than three lines of chemotherapy, and 33.5\% received chemotherapy for more than 1 year.

Patients with a history of TKI treatment (2,002 patients) were classified as the TKI group, and the remaining 979 patients without a history of TKI treatment were classified as the cytotoxic group. In the TKI group, 1,514 patients $(75.6 \%)$ received gefitinib treatment only, 367 patients $(18.3 \%)$ received erlotinib treatment only, and 121 patients (6.0\%) had received both gefitinib and erlotinib treatments. Among the total study population, 46 patients developed herpes zoster after the initiation of chemotherapy, and the overall frequency of herpes zoster was $1.54 \%$. The frequency of herpes zoster was not different based on sex, age, smoking history, ECOG performance status, initial status, and previous radiotherapy history in both the TKI and cytotoxic groups. However, the frequency was significantly different according to the number of chemotherapy regimens in the cytotoxic group. In both groups, the frequency of herpes zoster was significantly higher with a longer duration of chemotherapy. 
A
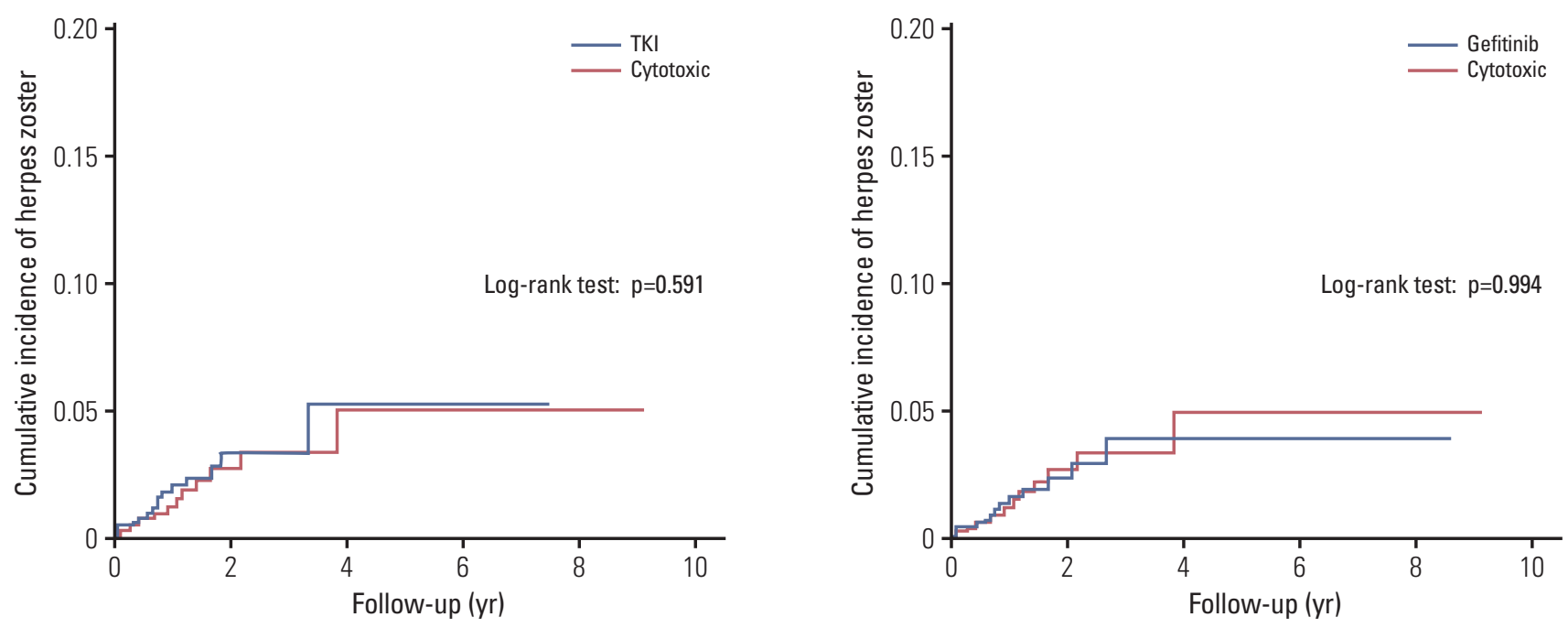

C

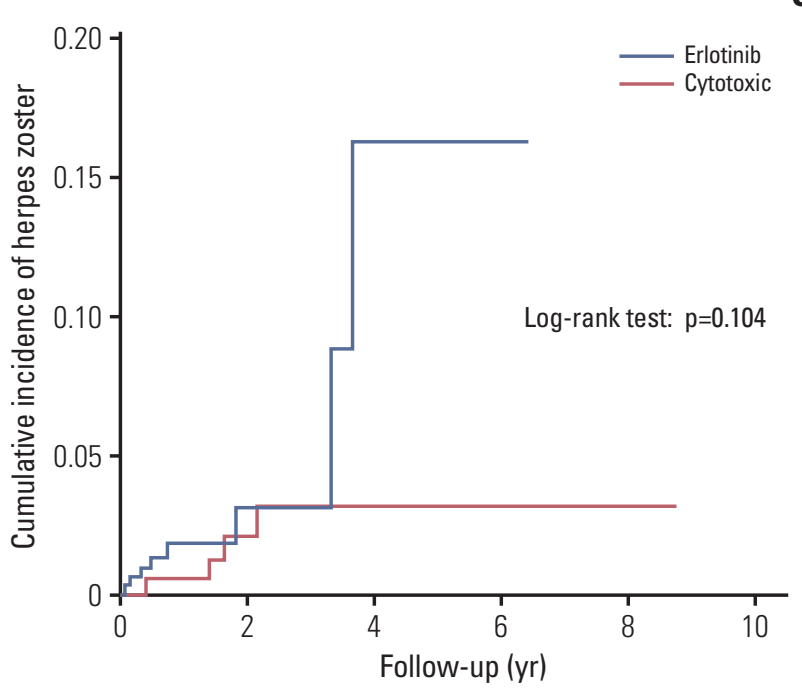

Fig. 2. The Kaplan-Meier cumulative incidence of herpes zoster plotted to compare the tyrosine kinase inhibitor (TKI) group and cytotoxic group (A), gefitinib group and cytotoxic group (B), and erlotinib group and cytotoxic group (C).

\section{Risk of herpes zoster during the use of TKI and cytotoxic regimens}

We compared the incidence of herpes zoster during the TKI regimen period with that during the cytotoxic regimen period in the TKI group. TKI/ cytotoxic regimen period was defined as the period during which patients are currently receiving TKI/cytotoxic regimen without discontinuation. The incidence rate during the TKI regimen period was 1.35 per $100 \mathrm{PY}$, and the incidence rate during the cytotoxic regi- men period was 1.28 per 100 PY. The IRR of the TKI regimen period to the cytotoxic regimen period was 1.05 (95\% CI, 0.53 to 2.09), suggesting that that there was no significant difference in the occurrence of herpes zoster according to the treatment regimen (Table 2).

To determine whether there was a difference in the incidence of herpes zoster according to the type of EGFR TKI, we performed a subgroup analysis of 1,635 patients with a history of gefitinib therapy and 488 patients with a history of erlotinib therapy. Compared to the incidence rate of her- 
Table 4. Incidence rates of herpes zoster in the TKI (including subgroups) and cytotoxic groups

\begin{tabular}{|c|c|c|c|c|c|c|c|c|}
\hline & \multicolumn{4}{|c|}{ Before matching } & \multicolumn{4}{|c|}{ After matching } \\
\hline & No. & No. of events & PY & IR (per 100 PY) & No. & No. of events & PY & IR (per 100 PY) \\
\hline TKI group & 2,002 & 33 & 2,318 & 1.42 & 979 & 16 & 1,033 & 1.55 \\
\hline Cytotoxic group & 979 & 13 & 1,114 & 1.17 & 979 & 13 & 1,114 & 1.17 \\
\hline $\begin{array}{l}\text { IRR }(95 \% \text { CI), TKI vs. } \\
\text { cytotoxic group }\end{array}$ & & & & $1.22(0.64-2.32)$ & & & & $1.33(0.64-2.76)$ \\
\hline Gefitinib group & 1,635 & 25 & 2,015 & 1.24 & 979 & 15 & 1,106 & 1.36 \\
\hline Cytotoxic group & 979 & 13 & 1,114 & 1.17 & 979 & 13 & 1,114 & 1.17 \\
\hline $\begin{array}{l}\text { IRR }(95 \% \mathrm{CI}) \text {, gefitinib } \\
\text { vs. cytotoxic group }\end{array}$ & & & & $1.06(0.54-2.08)$ & & & & $1.16(0.55-2.44)$ \\
\hline Erlotinib group & 488 & 9 & 437 & 2.06 & 488 & 9 & 437 & 2.06 \\
\hline Cytotoxic group & 979 & 13 & 1,114 & 1.17 & 488 & 5 & 605 & 0.83 \\
\hline $\begin{array}{l}\text { IRR }(95 \% \mathrm{CI}) \text {, erlotinib } \\
\text { vs. cytotoxic group }\end{array}$ & & & & $1.77(0.76-4.13)$ & & & & $2.50(0.84-7.45)$ \\
\hline
\end{tabular}

TKI, tyrosine kinase inhibitor; PY, person-years; IR, incidence rate; IRR, incidence rate ratio; CI, confidence interval.

pes zoster during the cytotoxic regimen period, the IRR of incidence rate during gefitinib therapy was 1.07 (95\% CI, 0.47 to 2.43$)$ and that during erlotinib therapy was 1.28 (95\% CI, 0.36 to 4.55$)$, both of which were not significant.

\section{Longitudinal risk of herpes zoster in patients treated with the TKI and cytotoxic regimens}

To evaluate the longitudinal risk of herpes zoster, we compared the incidence rate of herpes zoster in the TKI group with that in the cytotoxic group by reviewing the occurrence of herpes zoster after chemotherapy. We performed propensity score matching to balance the covariates between the two groups, i.e. the clinical features shown in Table 3, and 979 individuals in both groups were matched. Prior to matching, the TKI group had a lower male ratio, a lower mean age, a higher percentage of smokers, and a higher percentage of previous radiotherapy treatments compared to the cytotoxic group. However, the difference between the TKI and the cytotoxic groups was reduced after matching.

After matching, the IRR of the TKI group, compared to the cytotoxic group, was 1.33 (95\% CI, 0.64 to 2.76), which meant that there was no significant difference in the longitudinal incidence rate of herpes zoster between the two groups. Moreover, the Kaplan-Meier cumulative risk of these two groups were not significantly different $(\mathrm{p}=0.591$, log-rank test) (Fig. 2A).

The IRR was also calculated using the subgroup analysis in which propensity matching was performed for the two subgroups of patients receiving gefitinib and erlotinib. There was no significant difference between the two TKI subgroups and the cytotoxic group (Table 4). When comparing the cumulative risks by Kaplan-Meier analysis, there was no significant difference between the TKI subgroups and the cytotoxic group (log-rank test; $\mathrm{p}=0.994$, gefitinib vs. cytotoxic; $\mathrm{p}=0.104$, erlotinib vs. cytotoxic) (Fig. $2 \mathrm{~B}$ and C).

\section{Discussion}

The incidence rate of herpes zoster has been reported to be higher in patients with malignancies and in patients who underwent cancer treatments compared to the general population. According to the retrospective study by Rusthoven et al. [21], the cumulative incidence rate of herpes zoster in their cancer patient cohort was 625 per $10^{5} \mathrm{PY}$, which was two to three times greater than that in the general population. Dunst et al. [22] reported the incidence rate of herpes zoster among breast cancer patients after radiotherapy to be $3.7 \%$ (41/1,555 patients), which was 3- to 5-fold higher than that in the general population. However, the association between the development of herpes zoster and chemotherapeutic agents has rarely been studied.

VZV is known to remain in its latent stage when VZV-specific cell-mediated immunity is potent. Accordingly, the host factors that cause serious disruption of cell-mediated immunity have been known as major risk factors of reactivation. Among cancer patients, patients with hematologic malignancies have been reported to have high frequencies of herpes zoster, possibly due to their compromised immune system. Although patients with solid tumors are relatively less at risk, patients receiving chemotherapy are at greater risk for 
herpes zoster [21,23]. A study that investigated herpes zoster infections in breast cancer patients treated with adjuvant chemotherapy reported 13- to 25-fold higher incidence compared to the incidence in the general population [24].

Masci et al. [24] further highlight the association between the immunosuppressive effects of chemotherapy and the incidence of herpes zoster by comparing the incidence during taxane-based treatment, anthracycline-based treatment, and cyclophosphamide/methotrexate/fluorouracil treatment. The incidence of herpes zoster was the highest during taxane-based treatment, which was considered to have the strongest immunosuppressive effect. The effect of immunemodulating agents on the occurrence of herpes zoster was also investigated in a study that reviewed the incidence of herpes zoster in patients with non-Hodgkin lymphoma (NHL). Among NHL patients, the patients receiving rituximab-containing chemotherapy had an increased short-term risk of herpes zoster compared to the patients receiving conventional chemotherapy [25]. It is speculated that rituximab, which causes B-cell depletion and disruption of cellular and humoral immunities, increases the risk of herpes zoster. Based on these findings, chemotherapy that suppresses the immune system is an important predisposing factor of herpes zoster.

Then it is reasonable to question whether TKIs, whose therapeutic mechanism is fundamentally different from cytotoxic chemotherapy, would impose comparable risk of herpes zoster. Even though there have been sporadic reports of reactivation of viral diseases during the use of TKIs, EGFR TKIs have been reported to have significantly fewer treatment-related severe adverse events, including neutropenia, compared to cytotoxic chemotherapy $[11,13,26]$. Moreover, EGFR TKIs have been reported to have anti-viral effects on several viral diseases. As EGFR TKIs can inhibit virus-associated EGFR signaling as well as cancer-associated EGFR signaling, they can interfere with the pathogenesis of viruses that involve the EGFR pathway. For HPV, erlotinib was found to prevent immortalization of human cervical epithelial cells by disrupting the EGFR pathway by which HPV oncoproteins stimulate cell growth [17]. For HCV, the tyrosine-based motif within the viral core protein was found to be essential for viral assembly by interacting with a membrane trafficking protein of host cells. Discovery of this motif and consequent experimental evidence that the interaction between viral and host proteins was hampered by the use of erlotinib suggest the potential use of TKIs as antivirals. Moreover, gefitinib was also shown to inhibit poxvirus infection because it blocks the interaction of the vaccinia growth factor of the virus and EGFR, which facilitates viral spreading [19]. Consequently, we anticipated that the use of EGFR TKIs would impose less of a burden on the development of herpes zoster than cytotoxic chemotherapy.
However, our data showed that the incidence during the use of EGFR TKIs was not significantly lower than that during the use of cytotoxic chemotherapy. We also found that the incorporation of TKIs into cytotoxic chemotherapy did not significantly reduce the longitudinal risk of herpes zoster in the present study. These findings suggest that EGFR TKIs may impose as significant a risk as cytotoxic chemotherapy for the development of herpes zoster during and after the treatment.

This study has several limitations. This was a retrospective study conducted in a single institution. We may underestimate the incidence of herpes zoster because herpes zoster that occurred during the period when the patient was not visiting the hospital was not included in the study. Potential confounding variables, such as smoking/drinking habits, social-economic status, level of immunosuppression, and underlying diseases other than lung cancer, were not fully reflected owing to limited information on medical records, and subanalysis according to the NSCLC subtype and various cytotoxic agents were not performed. However, a study population of about 3,000 patients and a follow-up period of up to 13 years increased the statistical reliability of the results and many important confounding factors including ECOG performance, operation history, and history of radiation therapy were controlled through propensity score matching. In addition, this was the first study to statistically analyze the incidence of herpes zoster in patients with NSCLC according to chemotherapy regimens, including TKIs and cytotoxic agents.

In conclusion, we found that the incidence of herpes zoster during the EGFR TKI regimen was not significantly lower than that during the cytotoxic regimen in NSCLC patients. There was no difference in the longitudinal risk of herpes zoster between the TKI and cytotoxic groups. Although TKIs are generally thought to be more tolerable to immune-related cells than cytotoxic chemotherapy, our findings emphasize not to overlook the risk of herpes zoster in patients treated with EGFR TKIs. It is therefore worth closely monitoring patients treated with EGFR TKIs as carefully as patients treated with cytotoxic chemotherapy for preventing the development of herpes zoster.

\section{Conflicts of Interest}

Conflict of interest relevant to this article was not reported. 


\section{References}

1. Pinchinat S, Cebrian-Cuenca AM, Bricout H, Johnson RW. Similar herpes zoster incidence across Europe: results from a systematic literature review. BMC Infect Dis. 2013;13:170.

2. Yawn BP, Saddier P, Wollan PC, St Sauver JL, Kurland MJ, Sy LS. A population-based study of the incidence and complication rates of herpes zoster before zoster vaccine introduction. Mayo Clin Proc. 2007;82:1341-9.

3. Thomas SL, Hall AJ. What does epidemiology tell us about risk factors for herpes zoster? Lancet Infect Dis. 2004;4:26-33.

4. Rifkind D. The activation of varicella-zoster virus infections by immunosuppressive therapy. J Lab Clin Med. 1966;68: 463-74.

5. Glesby MJ, Moore RD, Chaisson RE. Clinical spectrum of herpes zoster in adults infected with human immunodeficiency virus. Clin Infect Dis. 1995;21:370-5.

6. Lin YH, Huang LM, Chang IS, Tsai FY, Lu CY, Shao PL, et al. Disease burden and epidemiology of herpes zoster in pre-vaccine Taiwan. Vaccine. 2010;28:1217-20.

7. Yenikomshian MA, Guignard AP, Haguinet F, LaCasce AS, Skarin AT, Trahey A, et al. The epidemiology of herpes zoster and its complications in Medicare cancer patients. BMC Infect Dis. 2015;15:106.

8. Sawyers C. Targeted cancer therapy. Nature. 2004;432:294-7.

9. Weinstein IB, Joe AK. Mechanisms of disease: Oncogene addiction: a rationale for molecular targeting in cancer therapy. Nat Clin Pract Oncol. 2006;3:448-57.

10. Cataldo VD, Gibbons DL, Perez-Soler R, Quintas-Cardama A. Treatment of non-small-cell lung cancer with erlotinib or gefitinib. N Engl J Med. 2011;364:947-55.

11. Wnorowski AM, de Souza A, Chachoua A, Cohen DE. The management of EGFR inhibitor adverse events: a case series and treatment paradigm. Int J Dermatol. 2012;51:223-32.

12. Kozuki T. Skin problems and EGFR-tyrosine kinase inhibitor. Jpn J Clin Oncol. 2016;46:291-8.

13. Bui N, Wong-Sefidan I. Reactivation of hepatitis B virus after withdrawal of erlotinib. Curr Oncol. 2015;22:430-2.

14. Neveu G, Barouch-Bentov R, Ziv-Av A, Gerber D, Jacob Y, Einav $S$. Identification and targeting of an interaction between a tyrosine motif within hepatitis $C$ virus core protein and AP2M1 essential for viral assembly. PLoS Pathog. 2012;8: e1002845.

15. Woodworth CD, Diefendorf LP, Jette DF, Mohammed A, Moses MA, Searleman SA, et al. Inhibition of the epidermal growth factor receptor by erlotinib prevents immortalization of human cervical cells by human papillomavirus type 16 .
Virology. 2011;421:19-27.

16. Lupberger J, Zeisel MB, Xiao F, Thumann C, Fofana I, Zona L, et al. EGFR and EphA2 are host factors for hepatitis $C$ virus entry and possible targets for antiviral therapy. Nat Med. 2011;17:589-95.

17. Langhammer S, Koban R, Yue C, Ellerbrok H. Inhibition of poxvirus spreading by the anti-tumor drug Gefitinib (Iressa). Antiviral Res. 2011;89:64-70.

18. Weller ML, Amornphimoltham P, Schmidt M, Wilson PA, Gutkind JS, Chiorini JA. Epidermal growth factor receptor is a co-receptor for adeno-associated virus serotype 6. Nat Med. 2010;16:662-4.

19. Keam B, Kim DW, Park JH, Lee JO, Kim TM, Lee SH, et al. How molecular understanding affects to prescribing patterns and clinical outcome of gefitinib in non-small cell lung cancer? 10 Year experience of single institution. Cancer Res Treat. 2013;45:178-85.

20. Keam B, Kim DW, Park JH, Lee JO, Kim TM, Lee SH, et al. Nomogram predicting clinical outcomes in non-small cell lung cancer patients treated with epidermal growth factor receptor tyrosine kinase inhibitors. Cancer Res Treat. 2014;46:323-30.

21. Rusthoven JJ, Ahlgren P, Elhakim T, Pinfold P, Reid J, Stewart $\mathrm{L}$, et al. Varicella-zoster infection in adult cancer patients: a population study. Arch Intern Med. 1988;148:1561-6.

22. Dunst J, Steil B, Furch S, Fach A, Bormann G, Marsch W. Herpes zoster in breast cancer patients after radiotherapy. Strahlenther Onkol. 2000;176:513-6.

23. Schimpff S, Serpick A, Stoler B, Rumack B, Mellin H, Joseph $\mathrm{JM}$, et al. Varicella-Zoster infection in patients with cancer. Ann Intern Med. 1972;76:241-54.

24. Masci G, Magagnoli M, Gullo G, Morenghi E, Garassino I, Simonelli M, et al. Herpes infections in breast cancer patients treated with adjuvant chemotherapy. Oncology. 2006;71: 164-7.

25. Cho SF, Wu WH, Yang YH, Liu YC, Hsiao HH, Chang CS. Longitudinal risk of herpes zoster in patients with nonHodgkin lymphoma receiving chemotherapy: a nationwide population-based study. Sci Rep. 2015;5:14008.

26. Rosell R, Carcereny E, Gervais R, Vergnenegre A, Massuti B, Felip E, et al. Erlotinib versus standard chemotherapy as firstline treatment for European patients with advanced EGFR mutation-positive non-small-cell lung cancer (EURTAC): a multicentre, open-label, randomised phase 3 trial. Lancet Oncol. 2012;13:239-46. 